\title{
Partnerships
}

\section{Limited partnerships and limited liability limited partnerships}

by Professor Johan Henning

\section{LIMITED LIABILITY \\ PARTNERSHIPS ACT 2000}

$\mathrm{T}$ the Limited Liability Partnerships Act 2000 (LLP 2000) received Royal Assent on 20 July 2000. It introduces a new corporate entity, carrying the designations 'partnership' and 'limited' but susceptible to neither the Partnership Act 1890 nor the Limited Partnership Act 1907, which will allow members to limit their liability whilst organising themselves internally as a partnership. The DTI expects the limited liability partnership (LLP) to be 'particularly popular with the professional business community'. Regulations governing LLPs are subject to affirmative resolution and will be laid before both Houses of Parliament after the summer recess. During Commons Report, Competition and Consumer Affairs Minister Dr Kim Howells confirmed that the new legislation would not be commenced until after the Inland Revenue have completed their review of alternative uses of LLPs where the primary or only attraction may be their tax status. However, it is not expected that this will delay the availability of LLPs beyond early 2001 .

The LLP was first mooted by the DTI in 1996, when it published a feasibility investigation of joint and several liability carried out by the Law Commission. Although the remit did not extend to the question of joint and several liability of partners, the DTI also consulted on whether to allow LLPs in the UK in the knowledge that the concept of LLPs was well-known, particularly in the USA. On 7 November 1996 an announcement was made of the Government's intention to bring forward legislation at the earliest opportunity to make LLPs available to regulated professions in the UK. Partners in an LLP would be able to take an active part in the management of the firm without incurring personal liability for other debts of the firm or the negligence of their partners.

As the Law Commission pointed out February 1997, the driving force behind this initiative of the DTI was the perceived vulnerability of a specialised set of users of partnerships, specifically large professional firms. Under partnership law, the personal assets of each and every member of a firm are at risk from the business decisions of their partners. This is the case despite the fact that it may very well be impossible for members to know all their partners and their work in a large professional partnership advising on major cross-border commercial transactions. At that time LLPs were already available in an increasing number of other jurisdictions and the DTI considered that UK professions would be at a competitive disadvantage without access to a similar form of association

\section{FUNDAMENTAL INNOVATION}

In its 1998 consultation document containing an innovative first Draft Limited Liability Partnership Bill (the Bill), the DTI described the LLP as 'the first fundamental innovation in this respect this century'. The LLP was favourably mentioned in the Queen's speech on 17 November 1999 at the State opening of Parliament. The Bill, now shorn of any limitation on availability to the regulated professions, was subsequently introduced into the House of Lords on 23 November
1999. The Bill was considered on Report in the House of Lords on 6 March 2000, when all Government amendments were agreed. The Bill received third reading in the House of Lords on 6 April 2000, with no amendments made. It was introduced in the House of Commons the same day, and received second reading on 23 May. The date for Committee was announced as 13 June 2000. Now the Bill has received Royal Assent, secondary legislation will have to be laid before Parliament, systems will have to be set in place to handle registration of LLPs and certain questions regarding LLPs' tax status await consultation and the possible introduction of legislation in the Finance Bill next year. Nevertheless, the DTI is confident that the LLP will become available in 2001 .

\section{MODERNISE LEGAL FRAMEWORK}

The objective of the LLP 2000 and the regulations is to modernise the legal framework for business in the UK, keeping it at the forefront of international practice by offering firms the ability to incorporate with limited liability while organising themselves on partnership lines, subject to provisions of the Companies Act 1985 and Insolvency Act 1986 on financial disclosure, fraudulent trading and winding up similar to those which apply to companies and their directors, thus providing safeguards to those dealing with the LLP.

Notwithstanding the term 'partnership' in its designation, the law of partnership will generally not be applicable to an LLP, although it will be taxed as a partnership to ensure that the choice between using an LLP or a partnership is a tax 
neutral one. The LLP will be required to disclose information on its finances and members, similar to that required of companies.

The first draft of the LLP Bill published in 1998 provided that the mutual rights and duties of members will be governed, inter alia, by the rules and principles which would apply if the 'law relating to partnerships' applied to them, and the property of the LLP were partnership property (clause 6(1)(c)) The redraft published in 1999 excludes this provision, because the general application of partnership law to LLPs is considered inappropriate for a number of reasons. The LLP will be a body corporate while partnership under the Partnership Act 1890 is generally treated (certainly in England if not in Scotland) as an aggregate of individuals. Thus the structure of the LLP will be different from that of a partnership. However, the Partnership Act is still the source of many of the draft default provisions governing the relationship between the members. The intention is to include these provisions in the main body of the LLP regulations. As in the case of partnerships, members will not be obliged to enter into any formal agreement. If they do enter into such an agreement, it need not be disclosed.

\section{AVAILABILITY}

In spite of the fact that the driving force behind the LLP legislation was the perceived vulnerability to major negligence claims of large professional partnerships, eligibility is no longer limited to the regulated professions. The stated intention now is that the LLP will be available to two or more persons carrying on any trade or profession. Although there are currently around 600,000 partnerships in the UK, the DTI believes that only a minority of these are likely to become LLPs. Consultation reveals that there is little or no interest in the new form of enterprise from the retail, manufacturing, catering and health sectors. The DTI expects LLPs to be attractive primarily to professionals such as lawyers, actuaries, patent and trademark agents, engineers, surveyors, architects and others in the construction industry. This may serve to strengthen persisting perceptions that the LLP may eventually still prove the be the almost exclusive preserve of large professional firms, although it should be noted that LLPs have had some success as a business vehicle in jurisdictions such as the United States, Canada and Australia. In his article, 'A new form of business association for the twenty-first century' (2000 Company Lawyer 39), Professor John Birds gives another interesting perspective on the LLP in this regard. He points out that, although the DTI's review of company law is taking special note of the needs of smaller companies, the current approach seems to be that the outcome will not be affected by separate legislation as has been done with considerable success in other jurisdictions, such as South Africa. It might, however, conceivably turn out that UK law will provide a new business vehicle by separate legislation which is a genuine and much better suited form of business enterprise for the small incorporated partnership. This may very well be the LLP, now that it is shorn of the limitation on its availability to the regulated professions only.

In any event, the incorporated LLP should not be confused with the unincorporated limited partnership (LP) provided for by the Limited Partnership Act 1907. The LP has not proven even remotely as popular in the UK as its more vociferous proponents would have wished. The LP consists of one or more general partners liable for all the debts and obligations of the firm, and who alone are entitled to manage the firm's affairs, and one of more limited partners whose liability for the debts and obligations of the firm is limited in amount but who are excluded from all management functions (Limited Partnership Act 1907 s.4(2)). In contradistinction, the LLP offers limited liability to all its members. Also, the members of an LLP will be able to take an active part in management without incurring unlimited personal liability for the debts and obligations of the LLP.

\section{CONCEPT}

The LLP concept originated in Texas in 1991 in unincorporated form, inspired by government litigation against law and accounting firms that had done work for failed savings and loan associations. The claims were against all partners including many who had nothing to do with the failed associations, highlighting the joint and several liability of partners for each other's conduct. The prospect that all the members in a partnership of attorneys or accountants may be exposed to hundreds of millions of dollars in liability was a strong incentive for the development of mechanisms to limit the vicarious liability of partners. The LLP is the device developed to accomplish that objective. It has proved very popular. In a short period of time, all US jurisdictions adopted legislation sharing the theme that an LLP limits or eliminates joint and several liability of partners for some, or all, liabilities and obligations of the partnership and that, for other purposes, it remains a general partnership regulated by either the Uniform Partnership Act 1914 (UPA) or the Revised Uniform Partnership Act 1994 (RUPA). Eventually, the National Conference of Commissioners on Uniform State Laws approved the Uniform Limited Liability Partnership Amendments (ULLPA) to the RUPA in 1996.

At the time RUPA was first approved in 1992, only two states had adopted limited liability partnership legislation. By the time the LLP amendments to RUPA were approved in 1996, over forty states had adopted limited liability partnership provisions to their 
general partnership statutes. The ULLPA amendments to RUPA deal with four major issues, namely the scope of a partner's liability shield, the voting requirement to become an LLP, the effect of becoming an LLP on the partnership agreement and the annual filing requirement. It should be noted that in contradistinction to the UK LLP, for all purposes other than the specially created partner liability shield, the LLP under the ULLPA is a general partnership. On the other hand, it should also be noted that in contradistinction to the general approach of English partnership law, the RUPA characterises even a non-LLP partnership as an 'entity' and not as a mere aggregate of individuals.
The LLP legislation of some US jurisdictions allow an LP to register as an LLP. The form of business association that results from such a registration is referred to as a limited liability limited partnership (LLLP). While the term 'partnership' does not include an LP, the ULLPA makes it clear that an LP may obtain LLP protection through limited partnership legislation incorporating the relevant ULLPA provisions by express reference. An LP may thus become an LLLP and its general partners will acquire the LLP's liability shield under the ULLPA. Determining the protection afforded to limited partners in a LLLP is a more complex matter which merits separate discussion. In any event, the ULLPA commentary suggests a specific amendment of LP legislation applying the same liability shield to both general and limited partners in an LLLP.

The arrival of the LLP on the legal scene in the UK is imminent. Whether the LLLP structure will eventually wend its way into UK LLP legislation, and resuscitate the UK LP in the process, remains to be seen. (8)

Professor Johan Henning

Director of the Centre for Corporate Law and

Practice, Institute of Advanced Legal Studies,

University of London. Dean of the Faculty of

Law, University of the Free State, South Africa.

\section{CCH@NEW LAW}

\section{Free trial @ wuw.cchnewlaw.co.uk}

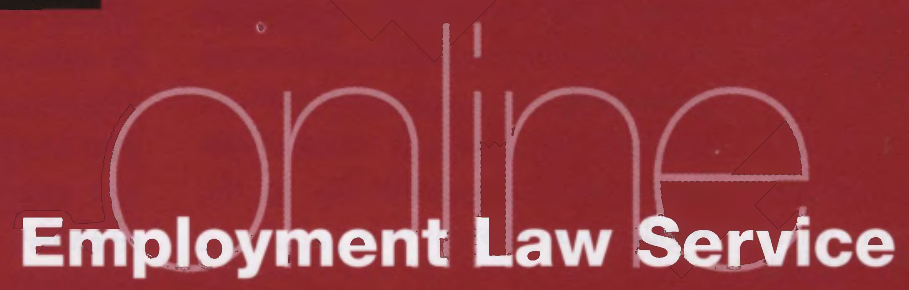

\section{Written by experts for experts Unrivalled coverage and speed of updating}

\section{COMING SOON ...}

- Legislation Database
- Single source research tool for the employment law practitioner

- Daily case reporting

- Current awareness service

- Personalised alert service
- Constantly updated commentary

- Forms and precedents

- Equivalent to 10 loose-leaf volumes

\section{Register now for a FREE TRIAL at www.cchnewlaw.co.uk}

